\title{
Dijagrama raspodele verovatnoće pogađanja pri izvođenju kuglaškog hica
}

Milan R. Pilipović

Trener ženskog kuglaškog kluba Apatin

\begin{abstract}
In this paper we will define and explain a number of criteria based on which we can analyze and evaluate the quality and the current state of the bowlers training. At the same time, such an analysis would indicate the nature of errors (random or systematic) that occur during the execution of the shot, and the impact of errors on the accuracy of the shot. The realization of this is the first step in the right advising by the coach to a players correct shots.
\end{abstract}

Keywords: bowling, shot, hit
Sažetak: U radu ćemo definisati i objasniti nekoliko kriterijuma na osnovu kojih se može analizirati i oceniti kvalitet i trenutna utreniranost kuglaša. Istovremeno ta analiza će nam ukazati na karakter grešaka (slučajna ili sistematska), koje se pojavljuju u toku izvođenja hica, kao i uticaj grešaka na preciznost izvođenja hica. Spoznaja navedenog je prvi korak u pravilnom davanju saveta trenera igraču za korekciju hica.

Ključne reči: kuglanje, hitac, pogodak

Rad je primljen 10.05.2016.

Odobren 18.05.2016.

Kontakt podaci:

Milan Pilipović

Ženski kuglaški klub "Apatin"

Apatin, Blok 112 Centar ulaz 2 stan 7,

Tel: +381645594803

E-mail: pilipovic@ptt.rs 


\section{Uvod}

Jedan od osnovnih zahteva koji se postavlja pred kuglaša jeste to da svaki hitac izvodi na isti način (izvodeći iste kretnje, postižući istu jačinu hica, isto mesto polaganja kugle, itd). U radu pod nazivom "Mehanika kuglaškog hica" detaljno je opisana geometrija trajektorije kugle i detaljno su analizirane mehaničke pojave koje utiču na nju (Pilipović, 2013). Preporuka je da putanja centra kugle na stazi bude pravolinijska i definisana je sa dve karakteristične tačke: tačka polaganja kugle (prvi kontakt kugle sa podlogom nakon ispuštanja iz ruke kuglaša) i tačka pogotka.

$\mathrm{Na}$ početku definisaćemo nekoliko tačaka, koje su prikazane na slici 1, a koje ćemo koristiti u daljnjem izlaganju.

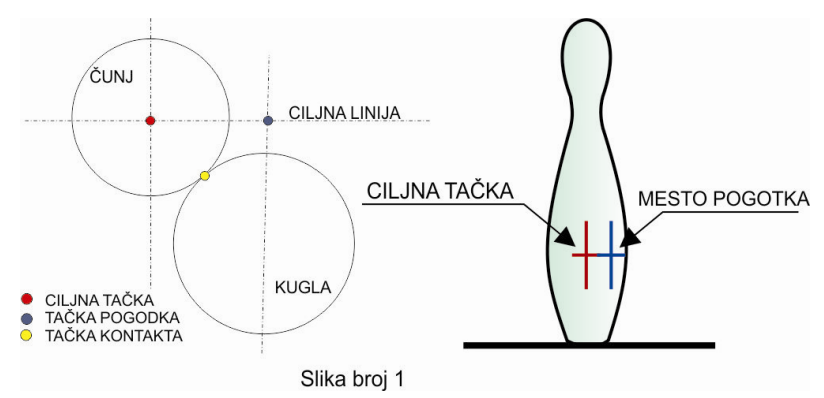

$\mathrm{Za}$ definisanje karakterističnih tačaka koristićemo središnju osu (u daljnjem tekstu "ciljna linija"), poprečnog preseka čunja broj "1" (prvi čunj), koja je normalna na osu staze.

Ciljna tačka - tačka na ciljnoj liniji kroz koju želimo da prođe centar kugle u izvedenom hicu.

Tačka pogotka - tačka na ciljnoj liniji kroz koju prolazi centar kugle u izvedenom hicu.

Tačka kontakta - tačka u kojoj dolazi do mehaničkog kontakta čunja i kugle u izvedenom hicu i razlikuje se od "tačke pogotka".

Tačka polaganja - tačka prvog kontakta kugle i podloge prilikom izvođenja hica (nakon ispuštanja kugle iz ruke kuglaša).

NAJVEĆE ODSTUPANJE (LEVO)

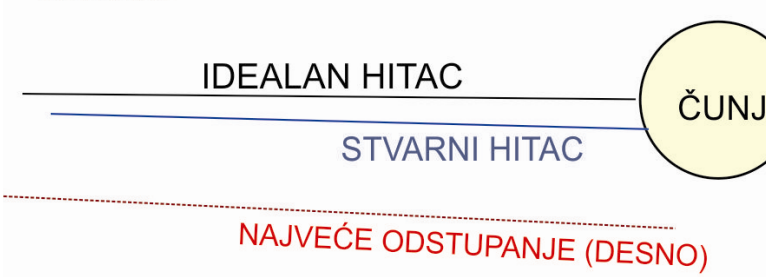

Slika broj 2
U zavisnosti od pozicije (raspored čunjeva na čunskom postolju pre izvođenja hica), postoji trajektorija centra kugle koju igrač želi da ostvari i to ćemo nazvati "idealan hitac". Idealan hitac je putanja centra kugle definisana sa dve tačke tačka polaganja i ciljna tačka.

Sa druge strane idealan hitac je hitac sa kojim se ostvaruje maksimalan učinak obaranja čunjeva u poziciji koju kuglaš gađa.

Stvarni hici kuglaša odstupaju od idealnog hica i njihov učinak je jednak ili manji od učinka idealno izvedenog hica. Ovaj hitac, takođe, definišu dve tačke i to: tačka polaganja i tačka pogotka.

Napominjemo da kada razmatramo preciznost izvođenja hica koristićemo "tačku pogotka", dok u razmatranju učinka obaranja čunjeva koristićemo "tačku kontakta" (Pilipović, 2013). Ove dve tačke nisu geometrijski vezane, što znači ako poznajemo jednu, druga se ne može jednoznačno odrediti.

Odstupanje stvarnog hica koji izvodi kuglaš od idealnog hica nazivamo "greškom", a nas posebno zanima greška koja predstavlja rastojanje između "ciljne tačke" i "tačke pogotka".

Maksimalna greška (levo i desno od ciljne tačke), predstavlja margine greške koje definišu opseg u kome se nalaze svi hici izvedeni od strane kuglaša.

Sada možemo definisati prvu važnu karakteristiku na osnovu koje možemo ocenjivati trenutnu utreniranost kuglaša, a to su margine greške prilikom izvođenja hica, odnosno, širina opsega u kome se stvarni hici kuglaša rasipaju u odnosu na idealan hitac.

Naravno što je opseg u kome se nalaze tačke pogađanja kuglaša manji, reč je o kvalitetnijem kuglašu.

Da bismo kompetentnije razmatrali kvalitet kuglaša, pored širine opsega moramo odrediti i raspodelu verovatnoćepoložaja tačaka pogađanja unutar definisanog opsega.

Pre nego što to uradimo, reći ćemo nekoliko reči o tome zašto nastaje greška, odnosno, zašto stvarni hici odstupaju od idealnog. Da bi se u hicu koji kuglaš izvodi postigao maksimalan učinak, taj hitac mora biti veoma blizu idealnom hicu. Koliko se hitac može razlikovati od idealnog, a da učinak ostane maksimalan, zavisi od pozicije čunjeva koje gađamo. Na primer kada gađamo poziciju sa čunjevima 1,3 i 6 odstupanje od idealnog hica može biti veće, nego kad gađamo poziciju sa čunjevima $1,3,4$ i 6 , i ako je ciljna tačka ista u oba slučaja.

I pored namere da izvede idealan hitac kuglaš u toku zaleta i izbacivanja kugle odstupa, često minimalno od željenih kretnji, što dovodi do 
krajnjeg rezultata da se tačka pogotka ne poklapa sa ciljnom tačkom. Mnogo je elemenata o kojima se mora voditi računa u toku zaleta da bi se hitac pravilno izveo.

Po pravilu u toku izvođenja svakog hica kuglaš učini jednu ili više grešaka koje u zbiru definišu konačno odstupanje stvarnog hica od idealnog. Razlikujemo dve vrste grešaka, i to: slučajne i sistematske.

Slučajne greške su greške koje koje se povremeno pojavljuju, bez pravlne zakonitosti njihove učestalosti $i$ intenziteta.

Sistematske greške su greške koje igrač ponavlja prilikom izvođenja više hitaca u nizu.

\section{Određivanje raspodele verovatnoće položaja tačaka pogađanja}

Da bi se odredila verovatnoća raspodele položaja tačaka pogađanja za konkretnog kuglaša, autor rada predlaže izvođenje vežbe, a zatim statističku analizu, sprovedeno na sledeći način.

VEŽBA - Na čunskom postolju se postavi čunj broj 1 i zadatak kuglaša je da ponavljajući u tri serije od po petnaest hitaca pogađa čunj postavljajući "ciljnu tačku" na središte čunja. Izvođenje serija dužih od petnaest hitaca se ne preporučuje, jer želimo da koncentracija kuglaša ostane maksimalna. Tri serije nam daju dovoljan broj hitaca na osnovu kojeg će statistička obrada odslikati realno stanje kuglaša.

ANALIZA VEŽBE - Prvo ćemo opseg rasipanja tačaka pogađanja izdeliti napoljakoja su prikazana na slici broj 3 .

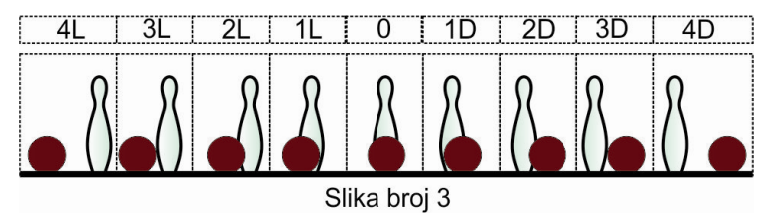

Širina polja na "ciljnoj liniji” iznosi približno $5 \mathrm{~cm}$, a označena su na sledeći način: " 0 " direktan pogodak, "1D" - debelo pogođen čunj sa desne strane, "2D" - tanko pogođen čunj sa desne strane, "3D" - mali promašaj sa desne strane, "4D" - veliki promašaj sa desne strane i analogno polja "1L", "2L", "3L" i "4L" sa leve strane.

Nakon svakog izvedenog hica beležimo polje u kome se nalazi tačka pogotka.Ovo pratimo vizuelno, a preciznija varijanta je ukoliko snimimo kamerom postavljenom $u$ blizini čunjskog postolja, tako da nakon puštanja usporenog snimka odredimo kom polju pripada tačka pogotka. Nakon završene vežbe dobijamo broj pogodaka svakog gore definisanog polja u vidu sledeće tabele.

\begin{tabular}{|c|c|c|c|c|c|c|c|c|c|}
\hline \multirow{2}{*}{$\begin{array}{l}\overleftrightarrow{\Xi} \\
\underset{\sim}{\Delta} \\
\underset{\sim}{\Delta}\end{array}$} & \multicolumn{9}{|c|}{ POLJA } \\
\hline & 4D & $3 \mathrm{~L}$ & $2 \mathrm{~L}$ & $1 \mathrm{~L}$ & 0 & $1 \mathrm{D}$ & $2 \mathrm{D}$ & $3 \mathrm{D}$ & $4 \mathrm{D}$ \\
\hline 1. & 0 & 1 & 1 & 3 & 6 & 2 & 2 & 0 & 0 \\
\hline 2. & 0 & 1 & 2 & 2 & 5 & 3 & 1 & 1 & 0 \\
\hline 3. & 0 & 0 & 1 & 3 & 6 & 3 & 2 & 0 & 0 \\
\hline$\Sigma$ & $\mathbf{0}$ & 2 & 4 & 8 & 17 & 8 & 5 & 1 & $\mathbf{0}$ \\
\hline
\end{tabular}

Sada ćemo odrediti relativnu frekvenciju pogodaka pojedinog polja koristeći sledeću formulu:

$$
f i=n i / \sum_{j=1}^{g} n j
$$

gdje su:

$f i$ - frekfencija pogodaka i-tog polja,

$n i$-broj pogodaka i-tog polja i

$$
\sum_{j=1}^{9} n j \text { ukupan broj izvedenih hitaca, }
$$

pri čemu je $\sum_{i=1}^{9} f t=1$.

Izračunate vrednosti frekfencija pogodaka pojedinog polja date su u sledećoj tabeli.

\begin{tabular}{|c|c|c|c|c|c|c|c|c|c|}
\hline & \multicolumn{10}{|c|}{ POLJA } \\
\cline { 2 - 11 } & 4D & $3 \mathrm{~L}$ & $2 \mathrm{~L}$ & $1 \mathrm{~L}$ & 0 & $1 \mathrm{D}$ & $2 \mathrm{D}$ & $3 \mathrm{D}$ & $4 \mathrm{D}$ \\
\hline ni & $\mathbf{0}$ & $\mathbf{2}$ & $\mathbf{4}$ & $\mathbf{8}$ & $\mathbf{1 7}$ & $\mathbf{8}$ & $\mathbf{5}$ & $\mathbf{1}$ & $\mathbf{0}$ \\
\hline fi & 0,0 & 0,04 & 0,09 & 0,18 & 0,38 & 0,18 & 0,11 & 0,02 & 0,0 \\
\hline
\end{tabular}

Dobijene rezultate ćemo prikazati i u vidu dijagrama raspodele verovatnoće pogađanja pojedinih polja, na sledeći način.

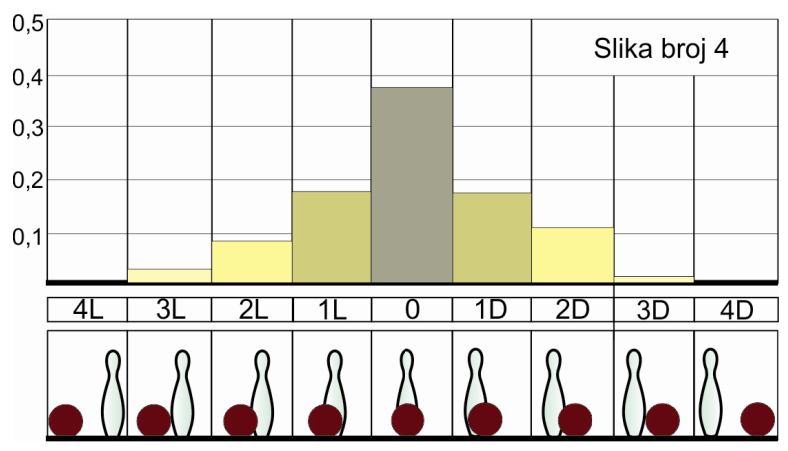

Pravilnim tumačenjem dijagrama prikazanog na slici broj 4 možemo precizno analizirati trenutnu utreniranost kuglaša, vodeći računa o sledećim pravilima:

- visina centralnog polja u dijagramu pokazuje verovatnoću sa kojom igrač pogađa polje u kome se nalazi ciljna tačka; 
- zbir visina ostalih pravougaonika pokazuje verovatnoću sa kojom kuglaš promašuje polje u kome se nalazi ciljna tačka;

- Što je centralno polje više znači da je igrač u boljoj formi, odnosno, da u toku izvođenja hica ima manji broj slučajnih grešaka, manjeg intenziteta (slika $5 \mathrm{~A}$ );

- Što su polja ujednačenija, igrač čini veći broj slučajnih grešaka, odnosno, reč je o igraču manjeg trenutnog kvaliteta (slika 5 B);

- ako je značajnije narušena simetričnost dijagrama ili ukoliko maksimalnu verovatnoću pogađanja igrač postiže u polju u kome se ne nalazi ciljna tačka, znači da postoji sistematska greška, pored slučajnih grešaka u toku izvođenja hica (slika 5 C i D).

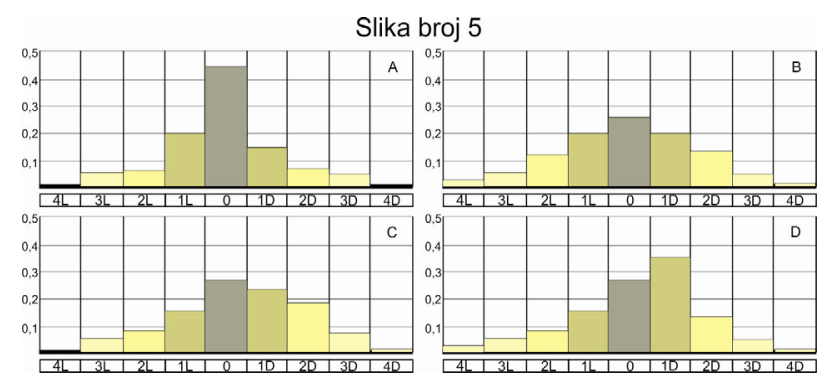

Treneri često daju savet kuglašu na osnovu uočene greške u kretnji u prethodnom hicu. Ukoliko se radi o sistematskoj grešci, korekcija će pomoći, jer se očekuje da je kuglaš ponovi u narednom hicu. Ako se radi o slučajnoj grešci, savet neće pomoći, jer je kuglaš verovatno neće ponoviti u narednom hicu.

Kompletnu vežbu možemo ponoviti postavljanjem krajnjih čunjeva 4 ili 6 umesto centralnog čunja broj 1 . Na ovaj način ćemo dobiti jasnu sliku odigravanja hitaca na levoj i desnoj strani čunskog postolja. Čest slučaj u praksi jeste da igrač slabije odigrava pozicije sa leve ili desne strane. Otkrivanje postojanja sistematske greške pri odigravanju jedne od strana je čest slučaj i najčešće je vezan za postavljanje igrača u početni položaj (Pilipović, 2013).

Druga varijacija ove vežbe jeste izvođenje svih 120 hitaca u kontinuitetu na jedan čunj. Poređenjem dijagrama raspodele verovatnoće pogađanja sačinjenih na osnovu 45 (3x15) i 120 hitaca pokazuje koliko zamor utiče na preciznost izvođenja hitaca kod igrača, a što daje dodatnu sliku o trenutnoj formi i kvalitetu igrača.
Dijagram raspodele verovatnoće pogađanja može da nam posluži i za izračunavanje verovatnoće obaranja određene pozicije (rasporeda čunjeva na čunskom postolju), što ćemo pokazati na sledećem primeru.

$\mathrm{U}$ istom primeru pokazaćemo koliko pravilno razmišljanje igrača i spoznaja svoje preciznosti mogu pomoći u podizanju verovatnoće obaranja pozicija, pogotovo kod manje kvalitetnih kuglaša.

PRIMER - Igrač za koga smo odredili u predhodnoj vežbi dijagram raspodele verovatnoće pogađanja treba da obori dva čunja, recimo čunjeve 1 i 2 (slika broj 6).

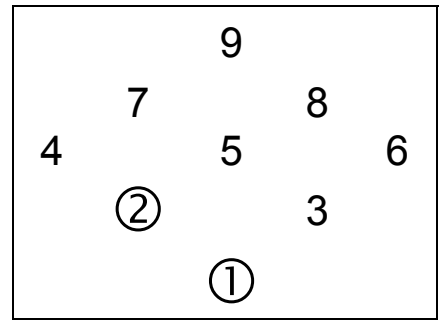

Slika broj 6

1. SLUČAJ -Igrač postavi ciljnu tačku između čunjeva 1 i 2 (onako kako se očekuje), a zatim izvede hitac. U tom slučaju oba čunja će biti oborena sa verovatnoćom $38 \%$, odnosno, onom verovatnćom kojom igrač pogađa " 0 " polje. Napominjemo da u ovom slučaju igrač obara poziciju sa dobro izvedenim hicem.

2. SLUČAJ - Igrač postavi ciljnu tačku na sredinu čunja 1 (onako kako se ne očekuje), a zatim izvede hitac. Verovatnoća obaranja oba čunja je zbir verovatnoća pogađanja polja "1L", “2L", “1D” i “2D”, odnosno, $56 \%$. Napominjemo da u ovom slučaju igrač obara oba čunja sa znatno većom verovatnoćom, ali sa hicem koji nije dobro izveden.

Ovakvim pristupom analizi preciznosti kuglaša može se objasniti ono što kuglaši iskustveno znaju, a to je da često igrač sa "lošijom igrom" ima bolji rezultat.

Važno je shvatiti da zahtevi koji se postavljaju pred kuglaša ne bi trebalo da budu formirani samo na osnovu pozicije koju treba da pogodi, već mora biti uzeta u obzir i individualna karakteristika igrača. 


\section{Zaključak}

Pristup analizi preciznosti kuglaša, koju definiše autor ovog rada, omogućava razvoj softvera koji bi obradom snimka hitaca, određivao raspodelu verovatnoće pogađanja, čime bi se eliminisala subjektivnost $\mathrm{u}$ oceni kvaliteta kuglaša.

Takođe, bilo bi moguće matematički odrediti položaj ciljne tačke ne samo na osnovu pozicije čunjeva (kako se to danas radi), već bi se uzela u obzir i individualna karakteristika kuglaša, čime bi se povećao. 


\section{Literatura}

1. Pilipović M., (2013) Mehanika kuglaškog hica, Aktuelno u praksi, Pokrajinski zavod za sport imedicine sporta, Novi Sad. 